\title{
Influence of the Alveolar Cleft Type on Preoperative Estimation Using 3D CT Assessment for Alveolar Cleft
}

\author{
Hang Suk Choi, Hyun Gon Choi, Soon Heum Kim, Hyung Jun Park, Dong Hyeok Shin, \\ Dong In Jo, Cheol Keun Kim, Ki Il Uhm \\ Department of Plastic and Reconstructive Surgery, Konkuk University School of Medicine, Seoul, Korea
}

Background The bone graft for the alveolar cleft has been accepted as one of the essential treatments for cleft lip patients. Precise preoperative measurement of the architecture and size of the bone defect in alveolar cleft has been considered helpful for increasing the success rate of bone grafting because those features may vary with the cleft type. Recently, some studies have reported on the usefulness of three-dimensional (3D) computed tomography (CT) assessment of alveolar bone defect; however, no study on the possible implication of the cleft type on the difference between the presumed and actual value has been conducted yet. We aimed to evaluate the clinical predictability of such measurement using 3D CT assessment according to the cleft type.

Methods The study consisted of 47 pediatric patients. The subjects were divided according to the cleft type. CT was performed before the graft operation and assessed using image analysis software. The statistical significance of the difference between the preoperative estimation and intraoperative measurement was analyzed.

Results The difference between the preoperative and intraoperative values were $-0.1 \pm 0.3$ $\mathrm{cm}^{3}(\mathrm{P}=0.084)$. There was no significant intergroup difference, but the groups with a cleft palate showed a significant difference of $-0.2 \pm 0.3 \mathrm{~cm}^{3}(P<0.05)$.

Conclusions Assessment of the alveolar cleft volume using 3D CT scan data and image analysis software can help in selecting the optimal graft procedure and extracting the correct volume of cancellous bone for grafting. Considering the cleft type, it would be helpful to extract an additional volume of $0.2 \mathrm{~cm}^{3}$ in the presence of a cleft palate.

Keywords Alveoloplasty / Bone transplantation / Cone-beam computed tomography
Correspondence: Ki II Uhm Department of Plastic and Reconstructive Surgery, Konkuk University School of Medicine, 120 Neungdong-ro, Gwangjin-gu, Seoul 143-729, Korea Tel: +82-2-2030-5235 Fax: +82-2-2030-5249 E-mail: kiumps@hanmail.net

The authors gratefully acknowledge the Korean Association of Plastic Surgeons Foundation for financial support of this article.

No potential conflict of interest relevant to this article was reported.

Received: 15 Jun 2012 - Revised: 11 Jul 2012 • Accepted: 25 Jul 2012

pISSN: 2234-6163 • elSSN: 2234-6171 • http://dx.doi.org/10.5999/aps.2012.39.5.477• Arch Plast Surg 2012;39:477-482

\section{INTRODUCTION}

An alveolar cleft occurs in $75 \%$ of patients with cleft lip, but it cannot be corrected using a standard operation for cleft lip or cleft palate [1]. Generally, the alveolar bone graft is considered to be an essential serial treatment for restoration of maxillary continuity and canine eruption.

The result of an alveolar bone graft is influenced by the timing of surgery, type of grafted bone, donor site, cleft type, size of the defect, status of tooth eruption on the cleft site, and skill of the

Copyright $($ C 2012 The Korean Society of Plastic and Reconstructive Surgeons

This is an Open Access article distributed under the terms of the Creative Commons Attribution Non-Commercial License (http://creativecommons.org/

licenses/by-nc/3.0/) which permits unrestricted non-commercial use, distribution, and reproduction in any medium, provided the original work is properly cited.

www.e-aps.org 
surgeon [2]. The mixed dentition period, when a $1 / 4$ to $1 / 2$ of the canine root has formed, is commonly seen as a satisfactory period in which to perform a bone graft $[3,4]$. Autogenous cancellous bone is widely used for the graft because it contains the functionality, including osteogenesis, osteoinduction, and osteoconduction, needed for a successful outcome [5]. Although autogenous bone may be harvested from various areas, the iliac crest is most frequently used because it provides abundant cancellous bone with high success rates of over 95\% [6].

As mentioned above, the success rate of a bone graft may be affected by the alveolar cleft type and size because the bone defect can vary with the shape and size of the cleft. Several studies have noted that the absorption rate of a grafted bone can be altered according to the cleft type [2]. Therefore, the preoperative measurement of the shape and size of the bone defect will be quite useful for a successful bone graft. Some recent studies have reported on the relationship between preoperative measurement of the cleft bone defect size using three-dimensional (3D) computed tomography (CT) assessment and the actual amount of grafted bone. However, no studies have considered the impact of the cleft type, which could cause erroneous differences between the defect size and the amount of grafted bone [7-9].

Therefore, we classified the alveolar cleft by whether cleft palate accompanied and compared the preoperative estimated volume (PEV) with the intraoperative measured volume (IMV) to determine whether the presence of the cleft palate could give rise to disparity in each value and how to apply the measurements to patients clinically.

\section{METHODS}

The study included 47 pediatric patients in their mixed dentition period who underwent alveolar bone grafts from March 2011 to May 2012. The patients were grouped according to bilaterality and concomitant cleft palate (Table 1).

A CT scan of the alveolar cleft was performed one month prior to the graft operation. The spacing of the CT images was set at $0.67 \mathrm{~mm}$. Two programs, Radipia 3D 2.8 (Infinitt Healthcare, Seoul, Korea) and Ondemand 3D 1.0 (Cybermed Inc., Seoul, Korea), were used for calculating the bone defect volume of the alveolar cleft in order to minimize errors. These programs have been used for calculating the volume in various clinical medical research fields [10]. These have worked by summing the area computed on each axial cut after determining the height of the defect on both the coronal and sagittal views. The formula was as follows $[11]$ : Volume $=\left[\mathrm{A}_{1} \times \mathrm{S}\right]+\left[\mathrm{A}_{2} \times \mathrm{S}\right]+\ldots+\left[\mathrm{A}_{\mathrm{n}} \times \mathrm{S}\right](\mathrm{A}$, area; $S$, space of the image; $0.67 \mathrm{~mm}$ and $\mathrm{n}$, number of images)

The height of the alveolar cleft was decided from the floor of the adjacent alveolar ridge to the highest point of the alveolar cleft or floor of the pyriform aperture when the cleft was extended to the pyriform aperture. The anterior-posterior dimension was set to the same thickness as the circumjacent normal

\begin{tabular}{|c|c|}
\hline Characteristics & Values \\
\hline \multicolumn{2}{|l|}{ Age (yr) } \\
\hline Average (range) & $9.8(8-11)$ \\
\hline \multicolumn{2}{|l|}{ Sex } \\
\hline Male & 29 \\
\hline Female & 18 \\
\hline \multicolumn{2}{|l|}{ Cleft type } \\
\hline Unilateral cleft lip and alveolus group & 13 \\
\hline Unilateral cleft lip and palate group & 18 \\
\hline Bilateral cleft lip and alveolus group & 2 \\
\hline Bilateral cleft lip and palate group & 14 \\
\hline
\end{tabular}

\section{Fig. 1. Preoperative computed tomography data}

The blue area indicates the defect site. $(A, B)$ The floor of the adjacent alveolar ridge defined the caudal margin of the defect. (C, D) The bottom of the pyriform aperture defined the cephalic margin of the alveolar cleft.
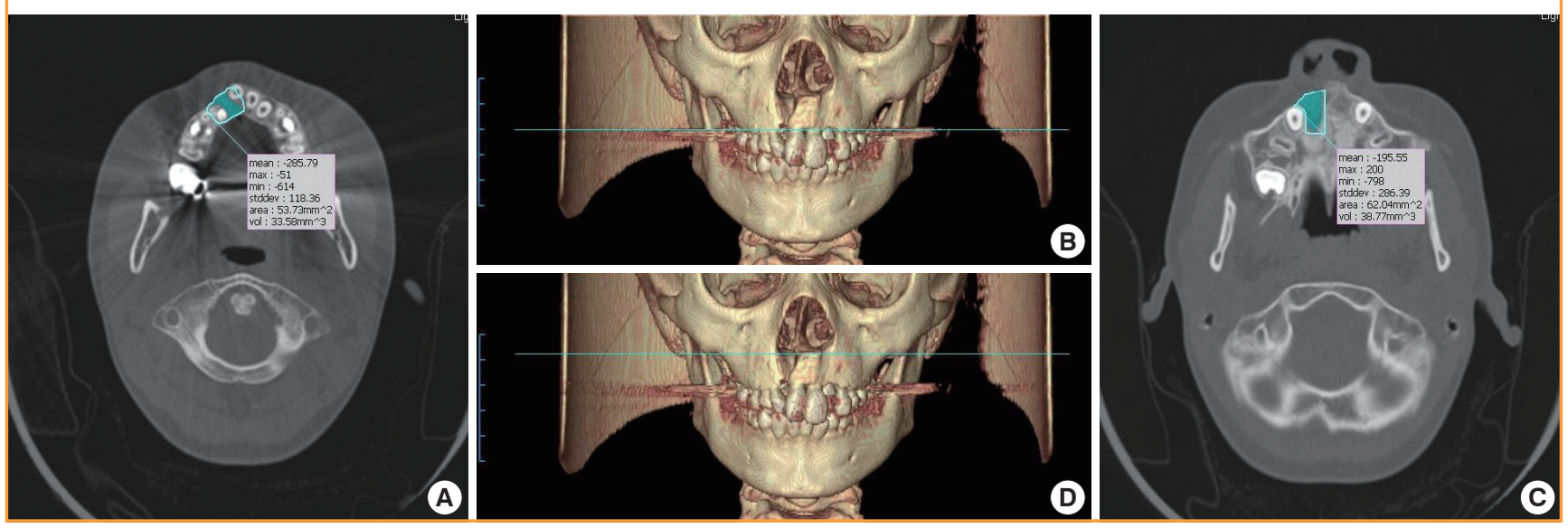
alveolar ridge. The bone defect in the hard palate was included in the calculations when a cleft palate accompanied the alveolar cleft (Fig. 1). All the measurements were performed by single plastic surgeon, and the mirroring system of the programs was applied to the unilateral cases. The staged operations were performed for the bilateral cases; however, only the data of the first operation was included in this study. The first operation site was selected randomly. The 3D architecture of the bone defect was

\section{Fig. 2. Preoperative 3D reconstruction of the alveolar cleft}

(A) Reconstruction of the cleft lip and alveolar in a patient. (B) Reconstruction of the cleft lip and palate in a patient. The defect size was larger and the bone defect extended to the hard palate.
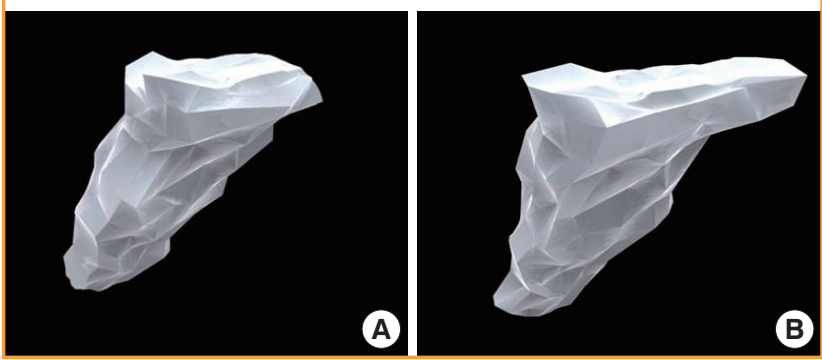

reconstructed with the same programs (Fig. 2).

All of the patients underwent rapid palatal expansion 6 months prior to surgery, and the senior author performed all of the operations. A surgical incision was made along the margin of the alveolar cleft from the central incisor anteriorly to the first molar posteriorly. The periosteal flap was dissected including the periosteum, and a vertical incision was made along the cleft margin, creating a mucoperiosteal flap. The flap base ensures sufficient flexibility to cover the bone graft without tension. The alveolar cleft was exposed through the vertical incision. The nasal floor was sutured and reconstructed as required. The anterior mucoperiosteal flap and palatal fistula were sutured with 5-0 Vicryl to form a pocket in which the bone graft could be located. The anterior iliac crest was used as the donor tissue in every patient. We harvested cancellous bone as chip bone using curettage. If the particles were too large, they were cut into small chip bones approximately $2 \times 2 \times 2 \mathrm{~mm}$ in size. The harvested bone was put into a $5 \mathrm{~mL}$ syringe filled with $2 \mathrm{~mL}$ of saline; the increased volume was then regarded as the harvested amount. The defect was filled with the harvested bone using gentle compression, and

\section{Fig. 3. Intraoperative photograph}

(A) The harvested cancellous bone chips approximately $2 \times 2 \times 2 \mathrm{~mm}$ in size. (B, C) The harvested bone was filled in syringe with $2 \mathrm{~mL}$ normal saline to measure the volume. (D) The alveolar bone defect prior to the cancellous bone graft. (E) The defect filled with cancellous bone chips. The cancellous bone was grafted in accordance with the maxillary contuor to avoid overcorrection.
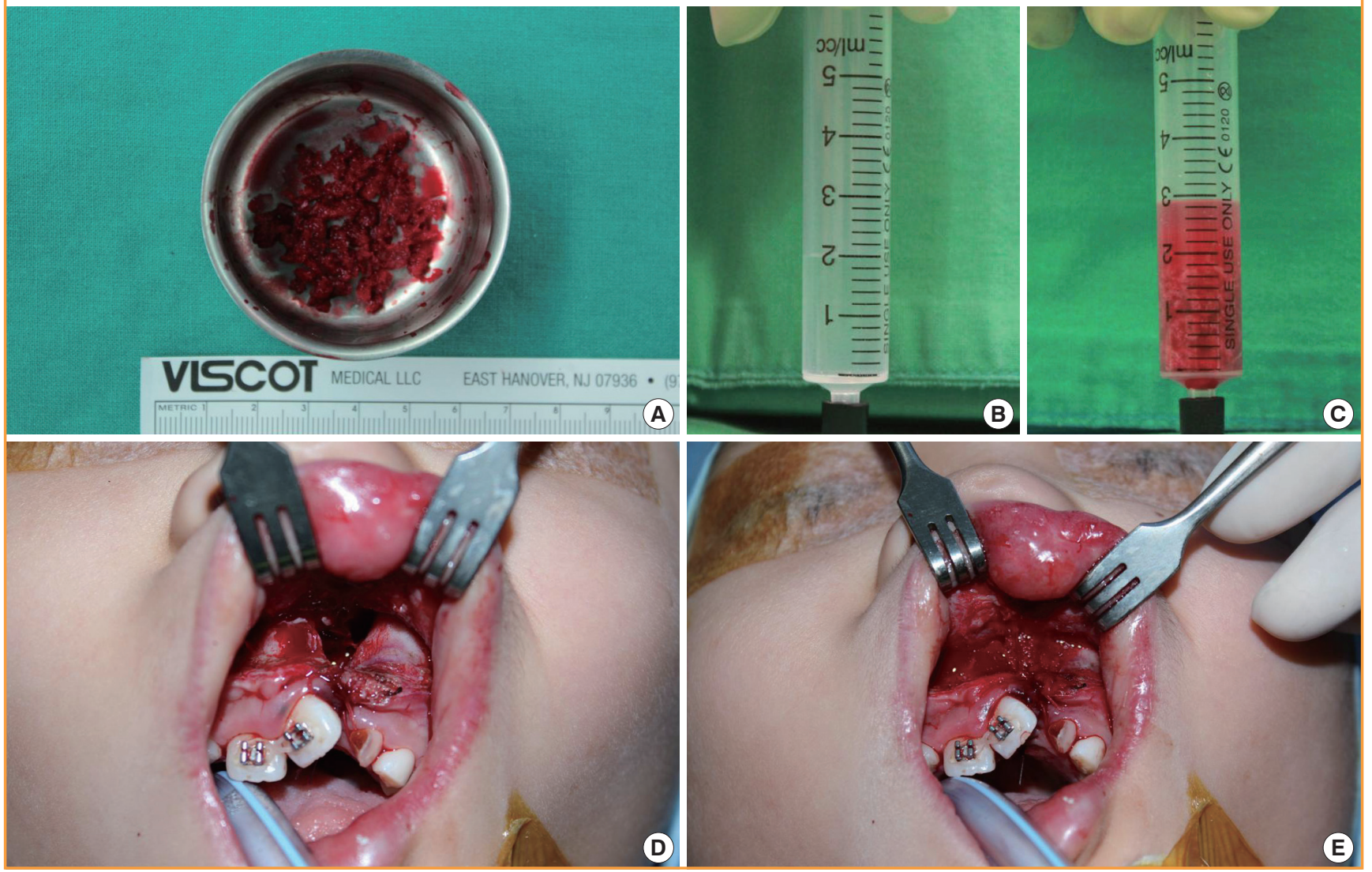
overfilling never ocurred (Fig. 3).

The statistical analysis of PEV and IMV was first performed to verify the two variables of bilaterality and presence of cleft palate, respectively. For statistical analysis, the paired sample t-test was performed with $95 \%$ confidence, and the Wilcoxon signed-rank test was performed when the number of patients was smaller than 30 . If statistical significance was shown, the effect of the other variable on the mean difference between the PEV and IMV was verified using the Mann-Whitney U test. All statistical analysis was performed with SPSS ver. 17 (SPSS Inc., Chicago, IL, USA).

\section{RESULTS}

The mean age of the patients was 9.8 years (range, 8 to 11 years), and 29 males and 18 females were included in this study. All 47 patients were categorized into 4 groups: unilateral cleft lip and alveolus (UCLA, $n=13$ ), unilateral cleft lip and palate (UCLP, $n=18$ ), bilateral cleft lip and alveolus (BCLA, $n=2)$, and bilateral cleft lip and palate (BCLP, $n=14)$ (Table 1$)$.

Individual data including PEV and IMV are shown in Table 2. There was no significant difference between PEVs calculated by the two programs: Radipia 3D 2.8 and Ondemand 3D 1.0 (Table 2). Overall, the mean values of PEV and IMV were $1.2 \pm 0.4$ $\mathrm{cm}^{3}$ and $1.3 \pm 0.5 \mathrm{~cm}^{3}$, respectively. The difference between the two values was $-0.1 \pm 0.3 \mathrm{~cm}^{3}$, which had no statistical significance with a P-value of 0.084 on a paired sample t-test. Compared with bilaterality, the difference between PEV and IMV was $-0.1 \pm 0.3 \mathrm{~cm}^{3}(\mathrm{P}=0.094)$ in the unilateral group and $-0.1 \pm 0.2$ $\mathrm{cm}^{3}(\mathrm{P}=0.474)$ in the bilateral group. Considering the type of accompanying cleft palate, the difference between PEV and IMV was $0.1 \pm 0.3 \mathrm{~cm}^{3}(\mathrm{P}=0.439)$ in the cleft lip and alveolus (CLA) group and $-0.2 \pm 0.3 \mathrm{~cm}^{3}(\mathrm{P}=0.007)$ in the cleft lip and palate (CLP) group. Only the CLP group showed a statistically significant difference on both the paired sample t-test and Wilcoxon signed-rank test (Table 3). The difference between PEV and IMV in the CLP group had no statistical significance $(\mathrm{P}=0.197)$ on the Mann-Whitney U test with bilaterality (Table 4 ).

\section{DISCUSSION}

Secondary alveolar bone grafting has many advantages such as excellent periodontal attachment to the adjacent teeth, restoring maxillary continuity, inducing dental eruption at the cleft site, giving aesthetic improvement through gingival recovery, and minimizing the interruption of facial growth $[12,13]$. These results can be achieved using an adequate volume of bone grafting material. An inadequate volume of grafted bone can cause graft
Table 2. Individual data including PEV and IMV

\begin{tabular}{|c|c|c|c|c|c|c|}
\hline Patient & Sex/Age & $\begin{array}{l}\text { Cleft } \\
\text { type }\end{array}$ & $\begin{array}{c}\text { PEV of } \\
\text { program } 1\end{array}$ & $\begin{array}{c}\text { PEV of } \\
\text { program } 2\end{array}$ & $\begin{array}{l}\text { Mean of } \\
\text { PEV }\end{array}$ & IMV \\
\hline 1 & $F / 10$ & UCLP & 1.6 & 2.0 & 1.8 & 1.5 \\
\hline 2 & $\mathrm{M} / 9$ & BCLA & 1.4 & 1.2 & 1.3 & 1.0 \\
\hline 3 & $\mathrm{M} / 11$ & BCLP & 1.8 & 1.8 & 1.8 & 2.1 \\
\hline 4 & $F / 11$ & UCLA & 1.0 & 1.0 & 1.0 & 1.1 \\
\hline 5 & $\mathrm{M} / 11$ & UCLP & 1.3 & 1.3 & 1.3 & 1.7 \\
\hline 6 & $F / 11$ & UCLP & 0.8 & 1.2 & 1.0 & 1.2 \\
\hline 7 & $\mathrm{M} / 8$ & UCLP & 1.0 & 1.1 & 1.1 & 0.8 \\
\hline 8 & $M / 10$ & UCLP & 0.8 & 1.2 & 1.0 & 1.5 \\
\hline 9 & $F / 10$ & UCLA & 0.6 & 0.6 & 0.8 & 0.6 \\
\hline 10 & $F / 9$ & UCLA & 1.3 & 1.1 & 1.2 & 0.8 \\
\hline 11 & $F / 9$ & UCLP & 1.3 & 2.0 & 1.8 & 2.0 \\
\hline 12 & $M / 9$ & BCLP & 1.4 & 0.7 & 1.0 & 1.1 \\
\hline 13 & $F / 9$ & UCLP & 1.5 & 1.1 & 1.3 & 1.6 \\
\hline 14 & $\mathrm{M} / 10$ & BCLP & 1.7 & 1.0 & 1.3 & 1.5 \\
\hline 15 & $M / 10$ & BCLP & 1.8 & 1.2 & 1.5 & 1.8 \\
\hline 16 & $F / 10$ & UCLP & 1.5 & 1.5 & 1.5 & 1.2 \\
\hline 17 & $F / 11$ & UCLP & 1.0 & 1.3 & 1.2 & 1.8 \\
\hline 18 & $M / 10$ & UCLP & 1.3 & 1.3 & 1.3 & 1.6 \\
\hline 19 & $\mathrm{~F} / 9$ & UCLP & 1.4 & 1.5 & 1.5 & 1.6 \\
\hline 20 & $\mathrm{~F} / 10$ & BCLP & 0.9 & 1.1 & 1.0 & 1.3 \\
\hline 21 & $F / 9$ & BCLA & 1.1 & 1.0 & 1.0 & 1.2 \\
\hline 22 & $F / 11$ & UCLP & 1.8 & 1.8 & 1.8 & 2.3 \\
\hline 23 & $M / 11$ & UCLA & 1.8 & 1.3 & 1.6 & 1.3 \\
\hline 24 & $\mathrm{M} / 10$ & BCLP & 0.7 & 0.9 & 0.8 & 0.7 \\
\hline 25 & $\mathrm{M} / 9$ & UCLA & 0.9 & 0.8 & 0.9 & 0.9 \\
\hline 26 & $\mathrm{M} / 11$ & UCLP & 1.1 & 1.2 & 1.2 & 1.4 \\
\hline 27 & $\mathrm{M} / 9$ & UCLA & 1.0 & 0.7 & 0.8 & 0.8 \\
\hline 28 & $\mathrm{M} / 10$ & BCLP & 1.9 & 1.5 & 1.6 & 1.3 \\
\hline 29 & $\mathrm{~F} / 8$ & BCLP & 1.8 & 1.8 & 1.8 & 2.2 \\
\hline 30 & $F / 8$ & BCLP & 0.5 & 0.7 & 0.6 & 0.6 \\
\hline 31 & $F / 9$ & UCLP & 1.0 & 1.0 & 1.4 & 1.1 \\
\hline 32 & $\mathrm{M} / 9$ & UCLA & 1.5 & 1.2 & 1.3 & 1.0 \\
\hline 33 & $\mathrm{M} / 10$ & UCLA & 0.7 & 0.7 & 0.7 & 0.9 \\
\hline 34 & $\mathrm{M} / 11$ & UCLP & 0.8 & 1.3 & 1.1 & 1.5 \\
\hline 35 & $\mathrm{M} / 10$ & UCLA & 1.0 & 0.8 & 0.9 & 0.6 \\
\hline 36 & $F / 9$ & UCLA & 1.0 & 0.6 & 0.7 & 0.7 \\
\hline 37 & $\mathrm{M} / 10$ & UCLA & 1.0 & 0.8 & 0.9 & 1.3 \\
\hline 38 & $\mathrm{M} / 10$ & BCLP & 1.9 & 1.9 & 1.9 & 1.5 \\
\hline 39 & $\mathrm{M} / 11$ & BCLP & 2.0 & 2.1 & 2.0 & 2.3 \\
\hline 40 & $\mathrm{M} / 9$ & UCLP & 1.5 & 1.9 & 1.7 & 2.1 \\
\hline 41 & $F / 11$ & UCLP & 0.6 & 1.0 & 0.8 & 1.3 \\
\hline 42 & $\mathrm{M} / 9$ & UCLP & 1.3 & 1.3 & 1.3 & 1.6 \\
\hline 43 & $\mathrm{M} / 10$ & UCLA & 1.3 & 1.3 & 1.3 & 1.8 \\
\hline 44 & $\mathrm{M} / 9$ & UCLA & 1.0 & 0.7 & 0.8 & 0.5 \\
\hline 45 & $M / 11$ & BCLP & 1.4 & 1.4 & 1.4 & 1.5 \\
\hline 46 & $\mathrm{M} / 10$ & BCLP & 1.7 & 1.9 & 1.8 & 1.6 \\
\hline 47 & $\mathrm{M} / 11$ & BCLP & 1.6 & 1.7 & 1.7 & 1.6 \\
\hline Mean & 9.8 & & 1.3 & 1.2 & 1.2 & 1.3 \\
\hline P-value & & & \multicolumn{2}{|c|}{$0.686^{a)}$} & 0.084 & \\
\hline
\end{tabular}

PEV, preoperative estimated volume; IMV, intraoperative measured volume; UCLP, unilateral cleft lip and palate group; BCLA, bilateral cleft lip and alveolus group; $\mathrm{BCLP}$, bilateral cleft lip and palate group; UCLA, unilateral cleft lip and alveolus group.

a)Paired-sample t-test.

failure, and grafting too much along with excessive compression can lead to inordinate resorption $[14,15]$. Harvesting too much 


\begin{tabular}{|c|c|c|c|c|}
\hline Value & $\begin{array}{l}\text { PEV } \\
\left(\mathrm{cm}^{3}\right)\end{array}$ & $\begin{array}{l}\text { IMV } \\
\left(\mathrm{cm}^{3}\right)\end{array}$ & $\begin{array}{l}\text { Difference } \\
\left(\mathrm{cm}^{3}\right)\end{array}$ & P-value \\
\hline Unilateral $(n=31)$ & $1.2 \pm 0.3$ & $1.3 \pm 0.5$ & $-0.1 \pm 0.3$ & $0.094^{\mathrm{a})}$ \\
\hline Bilateral $(n=16)$ & $1.4 \pm 0.4$ & $1.5 \pm 0.5$ & $-0.1 \pm 0.2$ & $0.474^{\text {b) }}$ \\
\hline $\mathrm{CLA}(n=15)$ & $1.0 \pm 0.3$ & $0.9 \pm 0.3$ & $0.1 \pm 0.3$ & $0.439^{b)}$ \\
\hline $\operatorname{CLP}(n=32)$ & $1.3 \pm 0.4$ & $1.5 \pm 0.4$ & $-0.2 \pm 0.3$ & $0.007^{\mathrm{a})}$ \\
\hline Total $(n=47)$ & $1.2 \pm 0.4$ & $1.3 \pm 0.5$ & $-0.1 \pm 0.3$ & $0.084^{a)}$ \\
\hline
\end{tabular}

Table 4. Mann-Whitney U test with group factor of bilaterality in CLP group

\begin{tabular}{lcccc}
\hline Bilaterality & $\mathbf{N}$ & Average of PEV-IMV & SD & P-value \\
\hline UCLP & 18 & -0.22 & 0.31 & 0.197 \\
BCLP & 14 & -0.13 & 0.26 & \\
CLP & 32 & & & \\
\hline
\end{tabular}

CLP, cleft lip and palate; PEV, preoperative estimated volume; IMV, intraoperative measured volume; SD, standard deviation; UCLP, unilateral cleft lip and palate; BCLP, bilateral cleft lip and palate.

bone or repeating the procedure with a small amount can also increase donor site morbidity. For these reasons, several studies have reported on the usefulness of the preoperative estimation of the bone defect volume on the alveolar cleft using 3D CT assessment. As mentioned above, the shape and size of the bone defect of an alveolar cleft can be adjusted according to the alveolar cleft type, but the alveolar cleft type that can influence the prediction procedure has never been considered.

Therefore, this study proceeded with the hypothesis that the alveolar cleft type has a certain effect on 3D CT assessment. The results showed that the overall PEV was not statistically different from the IMV $(\mathrm{P}=0.084)$ in all of the groups taken together, but there was a significant difference between them in the CLP group $(\mathrm{P}<0.05)$. The Mann-Whitney $\mathrm{U}$ test with bilaterality within the CLP group showed that there was no significant difference between the UCLP and BCLP groups $(\mathrm{P}=0.197)$ (Table 4). The underestimated volumes by 3D CT were $-0.2 \mathrm{~cm}^{3}$ in both the UCLP and BCLP groups. Considering that the overall mean value of the IMV was $1.3 \mathrm{~cm}^{3},-0.2 \mathrm{~cm}^{3}$ is not negligible. In several cases, after donor site repair, the iliac donor site was opened again to harvest $0.2 \mathrm{~cm}^{3}$ more bone during the operation; this can lead to donor site complications such as scarring and infection.

The size and structural disparity between the CLA and CLP group seemed to be an important factor for explaining the difference between the two groups. The mean value of the IMV $\left(1.5 \pm 0.4 \mathrm{~cm}^{3}\right)$ in the CLP group was larger, by as much as
Fig. 4. Sagittal view of the postoperative computed tomography scan

The white arrow indicates an overpacked bone graft toward the lingual side.

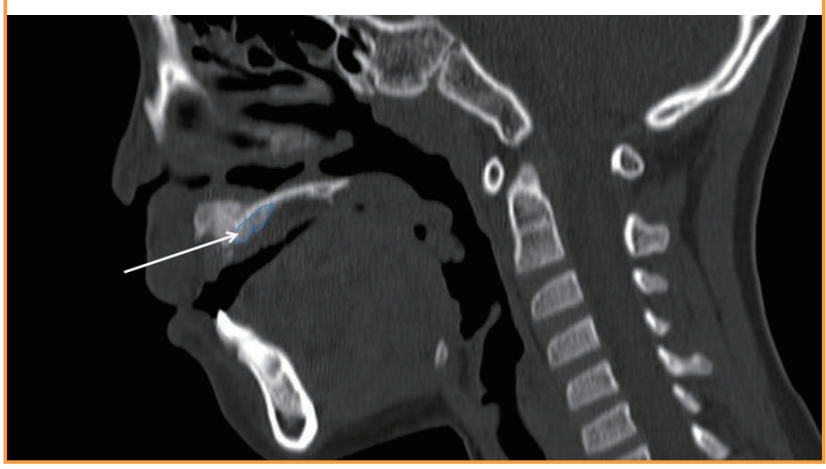

Fig. 5. Preoperative computed tomography scan

The white arrow indicates the lingual process.

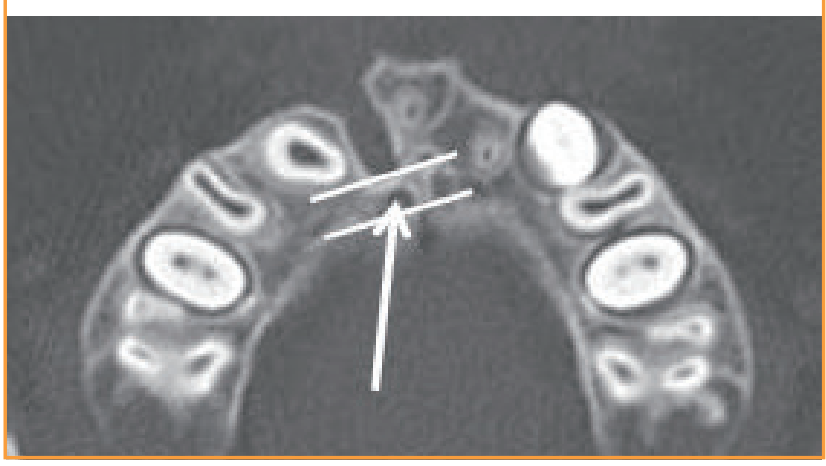

about $0.6 \mathrm{~cm}^{3}$, than that of the CLA group. This is regarded as one of the causes of the larger difference between PEV and IMV in the CLP group. The architecture of an alveolar bone defect is a pyramidal shape posteriorly bounded by an aveolus and the palate. On a reconstructed 3D image, when accompanied by a cleft palate, the bone defect was larger and extended to the hard palate (Fig. 2). In the past, some have advocated that strong compression and fine bony particles were necessary for a successful bone graft, but recently, several studies have reported that excessive crushing of cancellous bone can be harmful to the blood supply to the graft core and bony particles that are too tiny easily fail to revascularize and can be resorbed [14-16]. Thus, we tried not to apply excessive compression in order to avoid crushing the graft, and prepared the graft with bone chips of $2 \times 2 \times 2 \mathrm{~mm}$ to induce good revascularization (Fig. 3A) [16]. However, in the CLP group, packing the graft posteriorly tended to overpack into the soft tissue of the lingual side that had a weak support structure without strong compression (Fig. 4). It was thought that this phenomenon explained the significant difference between the PEV and IMV in the CLP group. 
Another structural disparity was the lingual process that was is a bony ridge on the lingual side of the alveolar cleft (Fig. 5). The process provides strong posterior support, which reduced the gap between the PEV and IMV in the CLA group. We observed the process in 13 of the 15 patients in the CLA group (87\%), but only in 1 of the 32 patients in the CLP group (3\%).

There is only one study that has reported on the usefulness of 3D CT assessment for alveolar cleft in vivo. Shirota et al. [7] performed late secondary bone grafting in 13 patients and suggested the usefulness of preoperative CT images by using image analysis software. Their patients' mean age was 22 years and the patients were in the period of late secondary bone grafting, not the mixed dentition period. Moreover, their study did not consider the cleft type. The results of the study showed a statistically insignificant difference of $-0.3 \mathrm{~cm}^{3}$ between PEV and IMV because the study only included adult patients; thus the larger margin of error could be permitted. Recently, the alveolar bone graft has been commonly performed in the mixed dentition period because the bone graft in this period never disturbs the maxillary growth, and the erupting canine gives functional stress to the graft, which increases the success rate [17]. Our study can support future guidelines for alveolar cleft treatment because we included only the patients in the mixed dentition period with a mean age of 9.8 years and prior to canine eruption.

The 3D CT assessment is a very reliable investigation tool, but it cannot interpret the variables of soft tissue and its elasticity because it focuses on the bony structure [8]. The purpose of this study is to demonstrate the application of 3D CT assessment clinically. As a result, the cleft type should be considered for determining the grafted volume using preoperative $3 \mathrm{D} C \mathrm{CT}$ assessment. Harvesting about $0.2 \mathrm{~cm}^{3}$ more bone for patients with a concomitant cleft palate is desirable based on our results.

\section{REFERENCES}

1. Bell WH, Proffit WR, White RP. Residual alveolar and palatal clefts. In: Bell WH, Proffit WR, White RP, editors. Surgical correction of dentofacial deformities. 1st ed. Philadelphia: Saunders; 1980. p. 1330.

2. van der Meij AW, Baart JA, Prahl-Andersen B, et al. Outcome of bone grafting in relation to cleft width in unilateral cleft lip and palate patients. Oral Surg Oral Med Oral Pathol Oral Radiol Endod 2003;96:19-25.

3. Ochs MW. Alveolar cleft bone grafting (Part II): secondary bone grafting. J Oral Maxillofac Surg 1996;54:83-8.

4. Kim SK. Secondary alveoloplasty using iliac cancellous bone graft in the cleft lip and palate patients. J Korean Cleft Palate-
Craniofac Assoc 2004;5:85-93.

5. Jun SH, Padwa BL, Jung YS. Alveolar cleft graft. J Korean Assoc Maxillofac Plast Reconstr Surg 2009;31:267-72.

6. Hoffman WY, Mount D. Cleft palate repair. In: Mathes SJ, editor. Plastic surgery. 2nd ed. California: Saunders; 2006. p. 264-6.

7. Shirota T, Kurabayashi H, Ogura H, et al. Analysis of bone volume using computer simulation system for secondary bone graft in alveolar cleft. Int J Oral Maxillofac Surg 2010; 39:904-8.

8. Albuquerque MA, Gaia BF, Cavalcanti MG. Oral cleft volumetric assessment by 3D multislice computed tomographic images. Int J Oral Maxillofac Surg 2011;40:1280-8.

9. Feichtinger M, Mossbock R, Karcher H. Evaluation of bone volume following bone grafting in patients with unilateral clefts of lip, alveolus and palate using a CT-guided threedimensional navigation system. J Craniomaxillofac Surg 2006;34:144-9.

10. Oh SH, Lee SS, Lee KJ, et al. Volume measurement of vestibular schwannoma using new software. Korean J Otolaryngol-Head Neck Surg 2002;45:451-5.

11. Feichtinger M, Mossbock R, Karcher H. Assessment of bone resorption after secondary alveolar bone grafting using threedimensional computed tomography: a three-year study. Cleft Palate Craniofac J 2007;44:142-8.

12. Kim JR, Jin SJ, Cho YC, et al. Clinical study of autogenous secondary bone grafting in cleft maxilla.J Korean Assoc Maxillofac Plast Reconstr Surg 2001;23:162-8.

13. Lee C, Crepeau RJ, Williams HB, et al. Alveolar cleft bone grafts: results and imprecisions of the dental radiograph. Plast Reconstr Surg 1995;96:1534-8.

14. Stassen LF. Alveolar bone grafting-how I do it. In: Booth PW, Hausamen JE, Schendel SA, editors. Maxillofacial surgery. Edinburgh: Churchill Livingstone; 1999. p. 1047-55.

15. Kim KR, Kim S, Baek SH. Change in grafted secondary alveolar bone in patients with UCLP and UCLA. A threedimensional computed tomography study. Angle Orthod 2008;78:631-40.

16. Fonseca RJ, Nelson JF, Clark PJ, et al. Revascularization and healing of onlay particulate allogeneic bone grafts in primates. J Oral Maxillofac Surg 1983;41:153-62.

17. Schultze-Mosgau S, Nkenke E, Schlegel AK, et al. Analysis of bone resorption after secondary alveolar cleft bone grafts before and after canine eruption in connection with orthodontic gap closure or prosthodontic treatment. J Oral Maxillofac Surg 2003;61:1245-8. 